\section{FUEROS Y ORDENAMIENTOS JURÍDICOS LOCALES EN ESPAÑA. UN PROYECTO INTEGRADOR}

\author{
Esteban Sarasa Sánchez \\ Vicepresidente de la CECEL
}

\begin{abstract}
In 2003, the CECEL started a scientist Project, coordinated by CECEL and developed by the confederate centres and entities, in order to study the "corpus" of the local charters and the related archives. The development of this Project is fully explained.
\end{abstract}

KEY WORDS: Charters. Codes. Crown. "Cartas Pueblas".

En el mes de septiembre del año 2003, tuvo lugar en Zaragoza la L Asamblea Anual de la Confederación Española de Centros de Estudios Locales, en el seno de la Institución Fernando el Católico de la Excma. Diputación Provincial de Zaragoza. Simultáneamente, alternando con las sesiones ordinarias de la Asamblea, acogiendo la propuesta del profesor Juan Ignacio Ruiz de la Peña Solar, se celebró un Congreso sobre Fueros y Ordenamientos Jurídicos Locales en la España Medieval, con la participación de estudiosos de las diversas universidades españolas y centros de investigación histórica y jurídica.

Para ello, se conformó un Comité Científico, bajo la presidencia de honor de don José María Font Rius, de la Universidad de Barcelona, y maestro en el tema objeto de dicho Congreso, quien, al no poder asistir por motivos de edad, se adhirió a la celebración y estuvo presente en la mente de los participantes, agradeciéndole, en los discursos de inauguración del Congreso, su labor realizada al respecto durante tantos años, así como la formación de discipulos que han continuado su investigación.

Los contenidos de las diversas ponencias expuestas a lo largo de los tres días de duración de la Asamblea antedicha y del Congreso en cuestión, se recogen ahora en esta publicación (Revista de Historia Jerónimo Zurita n. ${ }^{\text {s }} 78$ 79, Institución Fernando el Católico, Zaragoza 2003-2004,

\section{CHARTERS AND LOCAL CODES IN SPAIN, A PROJECT OF INTEGRATION}

RESUMEN: En 2003, la CECEL puso en marcha un proyecto científico que, bajo su coordinación, se desarrollara por los centros y entidades confederadas y estudiara el "corpus" de foralidad local y la archivística relacionada. Se da cuenta del desarrollo del proyecto.

PALABRAS CLAVE: Fueros. Ordenamientos jurídicos. Realengo. Cartas Pueblas.

400 pp.), que servirá de estado de la cuestión, punto de reflexión y de partida para los interesados en el estudio de los fueros y ordenamientos jurídicos locales en los reinos medievales españoles; correspondiendo (indistintamente) al número 3 de la Revista de la CECEL y asimismo al número 78-79... (ya mencionado).

Desgraciadamente, el profesor José Luis Martín Rodríguez, que participó entusiásticamente en el evento y envió su texto en tiempo y forma para su publicación, ha muerto antes de ver editadas las actas del Congreso y, por tanto, su propio texto. A él hacemos mención expresamente, en recuerdo de su magisterio y bonhomía".

Pues bien, así se presentaban los textos aludidos por parte de Ángela Madrid Medina (Presidenta de la CECEL y Directora del Instituto de Estudios Manchegos) y del que suscribe (en representación de la Institución Fernando el Católico, que fue la anfitriona). Sin mencionar entonces el sentimiento de no haber podido contar, entre otros, con el texto de Ruiz de la Peña, recogiendo su intervención solemne sobre el territorio asturiano, en el monasterio cisterciense de Veruela y al pie del Moncayo Becqueriano y Machadiano. Aunque, por lo demás, en la publicación queda representada la mayor parte de los reinos y coronas medievales; tal y como refleja el índice de la publicación: 
Forum Viator. Palabras de inauguración del Congreso..., por José Manuel Pérez-Prendes Muñoz-Arraco.

Ordenanzas locales en la Corona de Castilla, por MiguelÁngel Ladero Quesada.

Los archivos municipales: fuentes básicas para el estudio de los derechos locales en la Corona de Castilla, por César Álvarez Álvarez.

Los archivos nobiliarios y la edición y estudio de los derechos locales, por Gregoria Cavero Domínguez.

Horizontes matritenses del derecho de frontera, por Remedios Morán Martín.

Fueros locales de Navarra, por Luis Javier Fortún Pérez de Ciriza.

Ordenamientos jurídicos locales catalanes, por Tomás de Montagut Estragués.

Ordenamientos jurídicos locales aragoneses, por M. ${ }^{\text {a de los }}$ Desamparados Cabanes Pecourt.

Ordenamientos jurídicos locales valencianos, por Enric Guinot Rodríguez.

Ordenamiento jurídico en Castilla-La Mancha: Ia presencia de las órdenes militares, por Ángela Madrid Medina.

Ordenamientos jurídicos locales andaluces, por Manuel García Fernández.

Ordenamientos jurídicos de la "Extremadura" medieval, por José Luis Martín Rodríguez.

El derecho municipal como derecho del reino de Mallorca en la Edad Media, por Pau Cateura Bennàsser.

Ordenamientos jurídicos locales en el País Vasco y Cantabria, por José Ramón Díaz de Durana.

Las asociaciones interlocales y las cartas de hermandad como generadoras de derecho, por César González Mínguez.

Repertorio de títulos y contenidos que llenaron en su momento unas jornadas historiográficas, pero que, al mismo tiempo, ponían a punto un estado de la cuestión que, a su vez, debía servir de punto de partida para justificar un compromiso de la confederación, en cuanto a la responsabilidad de desarrollar un proyecto coordinado desde la CECEL y compartido entre los centros de estudios, institutos, academias e instituciones adscritas, conformando en conjunto:

a) un "corpus" de foralidad local, desde los repertorios ya publicados hacia la búsqueda en los archivos locales, provinciales y nacionales de textos inéditos por el momento, b) estados de la cuestión para los reinos y territorios desde la Edad Media en adelante y

c) estudios derivados de las nuevas fuentes de información y del conjunto de las ya conocidas.

Proyecto que, tras un tiempo de maduración y valoración en todos sus aspectos y frentes posibles a tener en cuenta, se ha comenzado ya a pergeñar con la invitación desde la comisión formada al efecto (e integrada por Ángela Madrid Medina, Carmelo Luis López, José Miguel López Villalba y Esteban Sarasa Sánchez), y en el marco del convenio suscrito entre la CECEL y la UNED (Universidad Nacional de Educación a Distancia), por ser ésta la única Universidad de implantación nacional y dependiente del Estado español; para que desde las respectivas sedes locales y provinciales de ambas instituciones se designen los responsables directos de la labor a emprender.

En definitiva se trata de abarcar hasta cinco etapas temporales que rebasan el tracto exclusivo medieval del Congreso de Zaragoza de 2003:

1. Edad Media: proceso repoblador tras la reconquista.

2. Siglo XVI: reordenación concejil y ordenanzas municipales.

3. Siglo XVII: repoblación consecuente con la expulsión morisca.

4. Siglo XVIII: proyectos ilustrados.

5. Colonización franquista.

No obstante, la principal dificultad del proyecto está en la falta de uniformidad que presenta actualmente el estudio de la foralidad y las colecciones documentales al respecto en los diferentes ámbitos objeto de atención. Por lo que se deben configurar diversos camspos de trabajo, que pueden dedicarse desde la recopilación bibliográfica a la documental, desde la edición crítica de grandes textos jurídicos a la preparación de estudios e investigaciones novedosos sobre la cuestión.

La dimensión espacial y temporal del proyecto se delimita entre la Edad Media y la postguerra civil española del siglo XX. Y para ello, a la hora de señalar los dos límites del mismo, se puede acudir para el comienzo a lo que José Manuel Pérez Prendes, en el trabajo inicial de las actas del Congreso de Zaragoza de 2003, cita a su vez del Ordenamiento de Alcalá del siglo XIV: 
"Porque al rey pertenece, e ha poder de facer fueros e leys, e de las interpretar e declarar, e emendar do viere que cumple, tenemos por bien que si en los dichos fueros, o en los libros de las (Siete) Partidas sobredichas, o en este nuestro libro, 0 en alguna, o en algunas leys de las que en el se contienen, fuere menester interpretación, o declaración, o emendar, o añadir, o tirar, o mudar, que nos que lo fagamos. Et si alguna contrariedad pareciere en las leys sobredichas entre sí mesmas, o en los fueros, o en qualquier dellos, o alguna duda fuere fallada en ellos, o algunt fecho porque por ellos non se puede librar, que nos seamos requeridos sobrello, por que fagamos interpretación, o declaración, o enmienda, do entendieramos que cumple, e fagamos ley nueva la que entendieremos que cumple sobre ello, porque la justicia, o el derecho sea guardado".

Añadiendo a continuación el referente del realengo al continuar que "nuestra Corte (la real) donde usan del fuero de las leys (Fuero Real) e algunas villas de nuestro sennorio lo han por fuero, e otras ciudades, e villas han otros fueros (locales) departidos". Y sin olvidar el señorío (laico o eclesiástico), pues "los fijosdalgo de nuestro regno han en algunas comarcas fuero de albedrío e otros fueros porque se juzgan ellos e sus vasallos" (Pérez-Prendes, obra citada, pp. 9 y 10).

De forma que, en estos textos del Ordenamiento de Alcalá de Alfonso XI, en 1348, se comprenden las claves de lo que para la corte y la justicia regia eran los principios de gobierno común y también los particulares, incluidos los señoriales.

Y en cuanto al franquismo, epílogo del proyecto anunciado, sirven, por ejemplo, las pautas adelantadas en el trabajo sobre La colonización franquista en la provincia de Toledo: los documentos para la configuración de un nuevo paisaje rural, al alcance de todos en el Archivo Histórico Provincial de Toledo (por Rita García Lozano, directora del AHP de Toledo, en Anaquel, n. ${ }^{\circ} 35,2006$, pp. 3 y 4); al decirse en el mismo que, en relación con Las fuentes de carácter primario como testigo directo del nacimiento de los pueblos nuevos:

"Pocas veces tenemos al alcance de nuestra mano la creación de un núcleo de población y la configuración de un nuevo paisaje y tipo de explotación agraria. Por lo tanto este fondo documental (se refiere al del AHP de Toledo) supone un conjunto homogéneo de documentos sobre una actua- ción concreta del franquismo, que supuso la transformación del paisaje agrario y el nacimiento de nuevos pueblos, con personas que venían de otros lugares y que aprendieron a convivir, surgiendo entre ellos el sentimiento de pertenencia a un nuevo lugar".

Así pues, desde la Edad Media hasta nuestros días, la temática elegida puede resultar inconmensurable, por la larga temporalidad y la diversidad y dispersión de las fuentes disponibles. Basta con recordar, por ejemplo, que para el último capítulo, el de la Colonización franquista, existen los proyectos de los arquitectos que trabajaron para el régimen y proyectaron los nuevos asentamientos con la infraestructura y servicios imprescindibles; los cuales pueden encontrarse en distintos lugares: familias de los propios proyectistas, colegios de arquitectos, archivos históricos provinciales, organismos de la administración del Estado o archivos de dicha administración (como el Archivo General de la Administración en Alcalá de Henares).

Sería deseable, además, que en el proyecto entrasen, de alguna forma -por ejemplo en el capítulo de la financiación de las publicaciones derivadas (repertorios, estudios, investigaciones, etc.)-, entidades como la Federación Española de Municipios y Provincias o el mismo Senado; por ser organismos de carácter representativo y participativo que recogen los intereses locales y provinciales de las diecisiete Comunidades Autónomas del Estado español, más Ceuta y Melilla.

Pero, tal y como ya se ha escrito anteriormente, volviendo al desarrollo inicial del proyecto, para la época medieval -que supone el fundamento del sistema de repoblación y organización concejil y aldeano a través de los fueros locales y cartas de poblamiento para los siglos posteriores, del XVI en adelante-, puesto que se trata de la implantación de un sistema jurídico ratificado en diversos momentos o readaptado según las circunstancias políticas y temporales, se cuenta, entre otras publicaciones, con tres ejemplos distintos para Castilla-La Mancha, Valencia o Aragón, por poner por caso.

En el primer caso se trata, no obstante, no de un mero repertorio o colección documental, que sí lo son, en cambio, los otros dos ejemplos; sino de un estudio, o conjunto de estudios, aplicable a cualquier fuero local o colección de fueros de la territorialidad medieval española correspon- 
diente; aunque contemplando las peculiaridades propias de cada territorio.

Al respecto, el título ya lo dice casi todo: Espacios y fueros en Castilla-La Mancha (siglos XI-XV). Una perspectiva metodológica (coordinador Javier Alvarado Planas, Editorial Polifemo, Madrid 1995); especialmente el subtítulo. Los contenidos, a cargo de varios colaboradores (recogiendo los textos de la ponencias del III Simposio de Historia de Castilla-La Mancha de 1994, sobre Derechos históricos de Castilla-La Mancha: una perspectiva metodológica, siglos XI-XV), se distribuyen en varios apartados:

I. La organización del espacio: el método.

II. La vertebración jurídica del espacio. Fueros y Cartas Pueblas castellano-manchegos.

III. Instituciones de Derecho Público.

IV. Instituciones de Derecho Privado, Penal y Procesal.

V. El espacio y el otro.

VI. Microespacios y derecho.

VII. Fuentes y fondos documentales.

Apartados que ya de por sí sugieren los propios contenidos y, sobre todo, la orientación metodológica. Pero con el enriquecimiento de que, al final de tan voluminosa obra (702 pp.), y a modo de apéndice, se ofrece un catálogo de Fueros y Cartas Pueblas Medievales de Castilla-La Mancha, desde Alfonso VI (1065) hasta los Reyes Católicos (1504); más los fueros otorgados por las Órdenes Militares de Calatrava, San Juan y Santiago; los concedidos por la Iglesia de Toledo; los de los señoríos laicos y también los debidos a los propios concejos (apéndice a cargo de Teresa Orgaz Rodríguez, de la UNED, pp.679-688). Así como también, y de segundo apéndice, aparece un índice de documentos publicados en el volumen (con relación de las páginas en que se encuentran en el mismo).

Así pues, aparte del ya de por sí valor metodológico y de estado de la cuestión, el libro presenta varios textos, que van desde la Carta de los mozárabes de Toledo otorgada por Alfonso VI (el 19 de marzo de 1101), hasta las Ordenanzas de la Hermandad de los escribanos de Ciudad Real (del 2 de marzo de 1489); comprendiendo un total de 40 textos. Y, además, sin desmerecer el resto de las aportaciones, cabe señalar como puesta a punto de la cuestión, las contribuciones tituladas: ¿Cómo vive un fuero? ¿Cómo se estudia un fuero? (de José Manuel Pérez-Prendes) y El proceso de formación de los fueros municipales (de Ana María Barrero); por ser de utilidad, a modo de planteamiento, para cualquier territorialidad distinta a la castellano-manchega; siempre que se tenga en cuenta la particularidad añadida de cada reino, comunidad o concejo.

Es decir, que se sugiere la posibilidad de tener en cuenta este ¿modelo? (bien entendido el concepto) a la hora de rehacer o hacer de nuevo repertorios documentales forales o estudios sobre la foralidad municipal en cada caso. Sobre todo por tratarse en él de los aspectos más importantes a tener en cuenta, con rigurosidad pero también con la frescura que los textos jurídicos, frente a la opinión contraria, aún pueden ofrecer en sus relecturas aisladas o comparadas.

Y al respecto, puede resultar aceptable cual comienzo reflexivo, lo escrito en el título antedicho por Pérez-Prendes:

"Cuando se ha buscado el sentido de un texto foral..., se han contemplado siempre por los investigadores las relaciones jurídicas que el fuero intenta regular con sus preceptos.

Por otro lado y además, otra de las diversas formas de acercarse a un fuero tan legítima como cualquiera, sería proponerse descubrir o seguir la oculta o manifiesta sistematización mental que late en el fondo del trabajo que supuso el redactarlo. Pero tampoco es tal fórmula la que encuentro más feliz para descubrir el sentido del fuero.

Desde mi punto de vista, y eso es lo que he procurado hacer con un fuero breve (el de Santander) y otro extenso (el de Cuenca), la referencia básica más expresiva que puede tomarse son los sujetos del Derecho que el fuero contempla (rey; señor en su caso; vecinos cristianos, judíos o moros; extraños, etc.) y perfilar la dimensión que se otorga a cada una de las relaciones jurídicas permitidas, impuestas o prohibidas a cada cual.

Surge así, o al menos yo así lo creo, un mapa de repartos jurídicos de poder y de protección legal (no digo justa) de intereses, que facilita mucho nuestra correcta percepción de en beneficio de quien se orientó la obtención y disfrute de los recursos propios del espacio jurídico de cada fuero. Y eso, tanto desde el punto de vista interno a ese mismo espacio, como (si luego se procede a las debidas comparaciones) desde la perspectiva de la posible o imposible homogeneidad entre espacios geográficos y forales distintos" (obra citada, p. 57). 
Pues de eso se trata, teniendo en cuenta que la base imprescindible es la disponibilidad de buenas ediciones de los textos; sean extensos o breves, reales, señoriales o concejiles; mantenidos o actualizados. Porque, volviendo a Pérez-Prendes: "La crítica textual siempre será imprescindible. Ella nos confirma que este o el otro fuero ha copiado, o se ha inspirado o ha contradicho, según sea, a aquel 0 aquellos fueros. $Y$ esa seguridad es un dato de firmeza importante, que siempre constituirá algo imprescindible en la investigación" (ibidem).

Hay que decir en este aspecto que hoy en día ya se cuenta con buenas ediciones críticas de los principales textos forales hispánicos medievales para los diversos reinos peninsulares. En sus versiones originales en latín y en sus versiones posteriores romanceadas en el caso de que existan manuscritos contrastables al respecto. Además, también se dispone de publicaciones que recogen y estudian textos forales menores con suficiente rigor.

De la misma forma que, encuentros como el que se ha tomado aquí como ejemplo para Castilla-La Mancha, también se han tenido ya con mayor o menor extensión y repercusión. Así como sucede con ediciones de fueros importantes que se han presentado recientemente acompañadas de varios textos complementarios que estudian los diversos aspectos relacionados con el fuero en sí, el contexto histórico del mismo, la sociedad a la que se destinó, las instituciones contempladas en los capítulos y otros muchos temas de interés. Tal y como sucede, por ejemplo, con la reciente edición de Tiempo de Derecho foral en el sur aragonés: Ios fueros de Teruel y Albarracín (EI Justicia de Aragón e Ibercaja, 2 volúmenes); con la edición facsimilar del Fuero de Teruel publicado en 1950 y en Stockholm por Max Gorosch, y un volumen complementario de estudios que contiene diecisiete colaboraciones de varios autores.

Acaso este ejemplo sea una excepción, aunque existen otras publicaciones similares; pero, no obstante, de lo que se trata es de saber que ya hay material suficiente como para volver a interesarse por los fueros municipales y locales en general desde nuevas perspectivas y valoraciones; comenzando por considerar los repertorios disponibles, como los que se comentan a continuación y dentro de los otros dos ejemplos anunciados anteriormente.
Por eso, los otros dos ejemplos reseñados a continuación responden a una buena edición de textos que coinciden en la fecha de edición, 1991; con sendas presentaciones ajustadas, aunque breves. De manera que, tanto el ejemplo castellano-manchego largamente glosado, como los que a continuación se van a comentar, son dos formas de aplicación y desarrollo del proyecto CECEL-UNED que justifica esta amplia presentación del mismo.

Así, para Valencia se cuenta con el libro de Enric Guinot Rodríguez, Cartes de poblament medievals valencianes (Generalitat Valenciana 1991). El mismo presenta una amplia introducción en tres apartados sobre el contenido y características de esas cartas de población, objeto principal del libro, así como acerca de las peculiaridades de la repoblación valenciana; temática habitual en este autor y sobre lo que desde 1991 ha seguido publicando en diversas aportaciones. Aunque lo más interesante es, sin duda, la colección de 320 textos, con un índice cronológico final de las cartas de poblamiento valencianas conocidas para la época medieval, con la fecha y el lugar a que corresponden; más otros índices alfabético, toponímico y onomástico de gran utilidad.

En cuanto al libro Cartas de población del Reino de Aragón en los siglos medievales, de María Luisa Ledesma Rubio (Institución Fernando el Católico, Zaragoza 1991), tras su introducción correspondiente, ofrece hasta 247 textos, con un índice analítico de gran extensión y utilidad.

Por cierto que dicha colección medieval tiene su, relativa, proyección en la colectiva de El señorio en Aragón (16101640). Cartas de Población, I, a cargo de Ángela Atienza, Gregorio Colás y Eliseo Serrano (Institución Fernando el Católico 1998). Y si bien en este caso se recogen tan sólo 26 textos de mayor o menor extensión y de varios condados, ducados y señoríos aragoneses para unos pocos años, la obra en cuestión se puede considerar como un ejemplo de presentación parcial, pero concretada en una jurisdicción tan importante como la señorial, que es susceptible de trasladar a otros años y otras jurisdicciones. Aunque, por otro lado, en este caso se trata de una repoblación obligada por la expulsión de los moriscos y el vacio poblacional que provocó en muchos lugares; lo que también sirve como referencia para otras partes ante semejante circunstancia, de gran repercusión en lo jurídico, social y económico. 
Claro que, al respecto, no se debe olvidar que el punto de partida es precisamente la figura de José María Font Rius y su obra en dos volúmenes: Cartas de población y franquicia de Cataluña (CSIC, Madrid-Barcelona 1983). Con el precedente de Muñoz y Romero en su Colección de fueros municipales y cartas pueblas de Castilla, León, Corona de Aragón y Navarra (Madrid 1847), así como la Colección de fueros y cartas pueblas de España, por la Real Academia de la Historia (Madrid 1852). Y el consecuente, entre otros, del libro de Ana María Barrero y María Luz Alonso, Textos de derecho local en la Edad Media. Catálogo de fueros y costumbres municipales (CSIC, Madrid 1989).

Finalmente, sin ánimo de exclusivizar, ni tampoco de adelantar ahora lo que deberá constituir el final del proyecto CECEL-UNED, es decir: un conjunto de textos forales inéditos, o, en su caso, una revisión de los ya editados, más una serie de estudios y monografías al respecto, de carácter reflexivo y con el método adecuado; los tres ejemplos señalados (castellano-manchego, valenciano y aragonés) pueden servir, pues, de referentes, porque juntos ofrecen buena parte de las posibilidades de trabajo y edición que sobre los fueros locales y cartas de población se ofrecen al investigador y al estudioso, desde el campo del Derecho o de la Historia; la historia urbana o la rural, la política o la administrativa, la social o la económica.

Pero, de momento, valgan estas líneas para estimular al trabajo que conlleva el desarrollo del proyecto preparado; aunque también, modestamente, puede ser útil para cualquier investigador que, por su cuenta, aborde con interés y preparación el tema, se inserte 0 no en el susodicho proyecto. Porque, en definitiva, se trata de proseguir una corriente y un proceso que viene ocupando, con alternativas de interés o desinterés, a los historiadores propiamente dichos y a los historiadores del derecho desde el siglo pasado, si no antes incluso. Y sin olvidar a los paleógrafos y diplomatistas, que son los expertos en la presentación de los textos y en su crítica textual y formal.

Por tanto, queda claro que es la foralidad local, concejil o municipal, real o señorial el objeto del proyecto; porque, en lo que se refiere a las grandes compilaciones y los ordenamientos forales de referencia estatal (Fuero General de Navarra, Compilación foral aragonesa de 1247, Partidas u Ordenamiento de Alcalá), los mismos no son objeto de este proyecto; aunque en ellos se encuentren indirectamente los soportes generales de una legislación que, aun afectando al conjunto territorial de un estado, no deja de implicar también al miembro de un colectivo aldeano o urbano.

Recibido: Octubre de 2007

Aceptado: Mayo de 2008 